\title{
Os sentidos de viver com diabetes mellitus na carceragem: relatos de prisioneiros no Complexo Penitenciário da Papuda, Brasília-DF
}

The subjective perception of living with diabetes mellitus in prison: stories of inmates in the Papuda Penitenciary Complex, Brasilia-DF

Los percepción subjetiva de vivir con diabetes mellitus en la cárcel: relatos de prisioneros del Complejo Penitenciario de la Papuda, Brasilia-DF

Maria da Cruz Oliveira Ferreira ${ }^{1}$

RESUMO: Objetivo - O artigo apresenta os resultados de um estudo sobre a percepção subjetiva dos pacientes diabéticos que se encontram dentro do sistema prisional masculino do Distrito Federal, e sobre os desafios enfrentados na convivência com a enfermidade de que padecem, no ambiente do Complexo Penitenciário da Papuda. Métodos - Tratou-se de estudo exploratório-descritivo, de abordagem qualitativa e análise do discurso do sujeito coletivo. Resultados - Os resultados que emergiram foram: baixo conhecimento sobre a doença, portadores de DM maioria solteiro com DM há pelo menos 5 anos e carência de verificação na implantação dos objetivos e diretrizes da Política Nacional de Atenção Integral à Saúde das Pessoas Privadas de Liberdade no Sistema Prisional (PNAISP), no âmbito do Sistema Único de Saúde (SUS). Conclusão - O sistema prisional não está preparado para lidar com as condições especiais necessárias dos prisioneiros com diabetes mellitus

Palavras-chave: Prisões. Diabetes Mellitus. Direito à Saúde.

ABSTRACT: Objective: The article presents the results of a study on the subjective perception of diabetic patients within the male prison system of the Federal District and on the challenges faced in living with the disease in the context of the Penitentiary Complex of Papuda. Methods - The study used an exploratory-descriptive method, based on a qualitative approach and discourse analysis of the collective subject. Results: The main results were related to the low knowledge about the disease; DM individuals with DM for at least 5 years; and the lack of verification in the implementation of the objectives and guidelines of the National Policy for Comprehensive Health Care for Persons Deprived of Liberty Prison System (PNAISP), part of the Unified Health System (SUS). Conclusion - The prison system is not prepared to deal with the special needs of prisoners with diabetes mellitus.

Keywords: Prisions. Diabetes Mellitus. Right to Health.

RESUMEN: Objetivo: El artículo presenta los resultados de una investigación sobre la percepción subjetiva de los pacientes diabéticos que se encuentran en el sistema penitenciario masculino del Distrito Federal y sobre los desafíos enfrentados en la

\footnotetext{
${ }^{1}$ Enfermeira. Mestre em Saúde Coletiva pela Universidade de Brasília, Programa de Pós-Graduação em Saúde Coletiva, Brasília, DF. Email: mcof13@gmail.com
} 
convivencia con la enfermedad de que padecen en el contexto del Complejo Penitenciario de la Papuda. Métodos - Se trató de estudio exploratorio-descriptivo, de abordaje cualitativo y análisis del discurso del sujeto colectivo. Resultados - Los principales resultados alcanzados fueron: el bajo conocimiento sobre la enfermedad; los portadores de DM son de mayoría soltera con DM por lo menos 5 años; y la carencia de verificación en la implantación de los objetivos y directrices de la Política Nacional de Atención Integral a la Salud de las Personas Privadas de Libertad en (PNAISP), parte integrante del Sistema Único de Salud (SUS). Conclusión - El sistema penitenciario no está preparado para hacer frente a las condiciones especiales de los prisioneros con diabetes mellitus

Palabras-Ilave: Prisiones. Diabetes Mellitus. Derecho a la Salud.

\section{Introdução}

Um cidadão, após a prática de um crime sujeita-se, em um Estado Democrático de Direito, a um julgamento justo e, se condenado, ao cumprimento de sua pena. Perderá seu direito à liberdade pelo tempo imposto pela pena restritiva de liberdade, cabendo ao Poder Público, não apenas garantir a integridade física e psíquica daqueles que cumprem pena com o intuito de ressocialização, mas igualmente sua saúde, promovendo-a, prevenindo-a de qualquer agravo ou enfermidade e recuperando-a em caso de moléstia.

O Direito Humano à Saúde foi inserido na Constituição brasileira de 1988 consagrando-a como um direito de todos, não distinguindo qualquer pessoa, estando em liberdade ou confinada ao cárcere.

E, para a garantia da saúde das pessoas privadas de liberdade, é preciso que o Estado trace políticas e estratégias diferenciadas de acesso, proteção e promoção, visto que essa população não pode locomover-se rumo a um serviço de saúde, nem ser atingida pelas políticas destinadas à população em geral.

Aparece então, para essa população, o conceito de grupo vulnerável para a garantia do direito à saúde. A ideia de grupos vulneráveis está diretamente ligada à noção de direito humano e relaciona-se a duas situações de suscetibilidade: a desigualdade e a diferença (1). A Constituição Federal ao reconhecer a igualdade formal, reconhece também, em nome da pluralidade e da ausência de preconceitos, 0 combate à exclusão no âmbito das desigualdades materiais, e em nome da igualdade de justiça. É fundamental e legítimo que os grupos sociais portadores de especificidades 
e submetidos a desigualdades sejam sujeitos de proteção jurídica diferenciada que, por meio de políticas públicas garanta a sua inclusão social

Neste sentido, com o intuito de formular uma política capaz de atender essas peculiaridades e voltar-se ao desafio de garantia do direito à saúde das pessoas privadas de liberdade, o Brasil como signatário das Nações Unidas submete-se às Regras Mínimas para o tratamento de Prisioneiros aprovada no $1^{\circ}$ Congresso das Nações Unidas sobre Prevenção do Crime e Tratamento de Delinquentes, realizado em Genebra, em 1955, e aprovadas pelo Conselho Econômico e Social da ONU. Em 25 de maio de 1984, através da Resolução 1984/47 (2), o Conselho Econômico e Social aprovou treze procedimentos para a aplicação efetiva das regras mínimas.

Assim é que a Lei de Execução Penal - Lei n 7210 de 1984 (3) - já sinalizava sobre a atenção à saúde no ambiente prisional. A Constituição Federal de 1988 (4) e a Lei 8.080/90 (5) fortaleceram a necessidade de serviços de saúde em instituições prisionais. Os serviços de saúde nos estabelecimentos prisionais foram de fato garantido a partir da Portaria Interministerial no 1.777 (6) de 2003, que instituiu o Plano Nacional de Saúde no Sistema Penitenciário. Em 2013, foi lançada a Portaria Interministerial no 1679 (7) que "institui o grupo de trabalho interministerial para elaboração da Política Nacional de Saúde no Sistema Prisional e o Comitê Técnico Intersetorial de Assessoramento e Acompanhamento da Política Nacional de Saúde no Sistema Prisional". Os representantes deste grupo são formados por diferentes órgãos da União, comprovando a necessidade de construção e gestão de uma política de forma intersetorial.

Em 2 de janeiro de 2014, foi publicada pelo Ministério da Saúde a Portaria Interministerial n. 01, que "Institui a Política Nacional de Atenção Integral à Saúde das Pessoas Privadas de Liberdade no Sistema Prisional (PNAISP), no âmbito do Sistema Único de Saúde (SUS) " (8)

A PNAISP tem como princípios, dentre outros elencados no seu artigo $3^{\circ}$, o respeito aos direitos humanos e à justiça social (inciso I) e integralidade da atenção à saúde da população privada de liberdade no conjunto de ações de promoção, proteção, prevenção (inciso II). E uma importante diretriz dessa política, no que tange a garantia do direito à saúde, encontra-se no artigo 4ํㅜ, inciso II, determinando que o Poder Público 
atue no sentido de garantir a "atenção integral resolutiva, contínua e de qualidade às necessidades de saúde da população privada de liberdade no sistema prisional, com ênfase em atividades preventivas, sem prejuízo dos serviços assistenciais".

O Complexo Penitenciário da Papuda, em Brasília localiza-se em espaço de 600 hectares. O complexo é composto de 6 presídios: 1 feminino e 5 masculinos. Os presídios masculinos contam com uma população carcerária de 12.813 indivíduos ${ }^{9}$, superando em $85 \%$ sua capacidade (9), sendo que $0,54 \%$ portadores de Diabetes Mellitus.

Verificar a percepção subjetiva desses enfermos em regime de reclusão em relação à sua enfermidade e conhecer como se dá a aplicação do autocuidado dessa população sob o ponto de vista do direito à saúde são os objetivos deste trabalho, que será orientado pela hipótese de não haver condições ideias para o tratamento do enfermo no ambiente prisional.

\section{Metodologia}

Desenvolveu-se um estudo qualitativo, tendo como substrato os depoimentos e informações dos presos diabéticos, obtidos através de entrevista semiestruturada e aplicação de questionário.

A pesquisa foi desenvolvida no Complexo Penitenciário da Papuda, em Brasília, Distrito Federal, nos presídios I e II, no período entre 2014 e 2015.

Foram identificados 58 presos do sexo masculino portadores de DM, adultos reclusos em regime fechado, cadastrados na penitenciária Papuda.

Para a seleção dos pacientes a entrevistar, adotou-se como critério de inclusão os pacientes alfabetizados, com diagnóstico de Diabetes Mellitus, em tratamento medicamentoso sem interrupção, e que passaram por avaliação médica no Serviço Médico da carceragem, no ano de 2014.

Como critério de exclusão, os pacientes que se encontravam internados fora do presídio ou estivessem em cumprimento de pena em isolamento.

Contou-se com um total de 26 internos do sexo masculino com DM, brasileiros e em dia com os atendimentos médicos mensais. Durante a realização das entrevistas, 2 
internos diabéticos obtiveram progressão de regime, saindo do regime fechado para 0 semiaberto e foram excluídos do estudo, restando 26 sujeitos para a pesquisa.

Houve prévia autorização da direção do presídio para a obtenção dos dados bem como a permissão para as entrevistas.

Para a obtenção do índice de massa corporal (IMC) os pacientes presos foram pesados e medidos na Enfermaria do complexo e foi calculado através do quociente entre o peso (em $\mathrm{kg}$ ) e o quadrado da altura (em m2). Utilizou-se a classificação da Organização Mundial da Saúde - OMS para o IMC, para definir baixo peso (IMC <18,5 $\mathrm{kg} / \mathrm{m} 2$ ), peso normal (IMC 18,5-24,9 kg/ m2), excesso de peso (IMC 25-29,9 kg/ m2) e obesidade (IMC>30 kg/ m2).

O lapso temporal escolhido para a aplicação das entrevistas foi entre os meses de janeiro, fevereiro e março de 2014, durante as consultas de enfermagem e realização de exames de rotina. O contato pessoal foi possível em vista de uma das autoras atuar como enfermeira no complexo penitenciário.

Aplicou-se questionário com questões psicossociais e entrevista semiestruturada. Para Gil (10), o questionário constitui uma das mais importantes técnicas disponíveis para a obtenção de dados nas pesquisas sociais. Pode-se definir questionário como a técnica de investigação composta por um número mais ou menos elevado de questões apresentadas por escrito às pessoas, tendo por objetivo o conhecimento de opiniões, crenças, sentimentos, interesses, expectativas, situações vivenciadas etc.

A pesquisa qualitativa busca compreender e explicar a dinâmica das relações sociais, por serem depositárias de crenças, valores, atitudes e hábitos, se preocupando com um nível de realidade que não pode ser quantificado, valorizando os processos e fenômenos, não se limitando a operacionalização de variáveis (11).

A entrevista semiestruturada teve como característica obter informações básicas de temas que se relacionam à pesquisa. Para a análise das respostas foi utilizado o método da Análise Idiossincrática de Canzonieri (12)

O projeto foi submetido ao Comitê de Ética em Pesquisa com Seres Humanos da Faculdade de Saúde da UnB. Todos assinaram o Termo de Consentimento Livre e Esclarecido e receberam explicações sobre a sua participação voluntária, garantindo a sua privacidade e protegida sua integridade física e moral. 


\section{Resultados e Discussão}

A coleta de dados se tornou demorada em vista da rotina imposta pelo regime penitenciário em prol da segurança. Embora garantido um espaço reservado, discreto e calmo para a aplicação das entrevistas em que cada participante teve liberdade para relatar sua condição de diabético e presidiário, houve durante as entrevistas o receio dos internos em participar do estudo, entendendo alguns que os relatos produzidos poderiam ser usados em seu desfavor, como membros de uma instituição penalizadora.

O baixo nível de escolaridade dos sujeitos entrevistados (ensino fundamental incompleto) não implicou no insuficiente conhecimento sobre o Diabetes Mellitus. Este resultado contrasta com outros estudos que demonstraram que o baixo nível de escolaridade na população carcerária dificulta o conhecimento e cuidado com a enfermidade com que padecem. (5), (6), (7), (8). No Brasil, a população carcerária tem grau de instrução até o Ensino Fundamental Completo compatível com os resultados encontrados. (9)

A idade média encontrada foi de 38.5, com idade mínima de 21 e máxima de 56 anos, e a condição civil de casado foi declarada por maioria no questionário. Albuquerque et al (13), em seus estudos na Penitenciária Juiz Plácido de Souza, em Caruaru/Pernambuco encontraram resultados semelhantes. No entanto, a idade de condenados institucionalizados no Brasil é entre 18 e 29 anos de idade.

A maioria dos entrevistados declarou-se fumante com consumo em cerca de 9 cigarros por dia. O número de fumantes coincide com os que têm excesso de peso. Associados ao cigarro, o uso de drogas ilícitas foi confirmado na maioria dos internos entrevistados. Vários estudos realizados em populações prisionais demonstram que a maioria dos reclusos são fumadores e obesos. (13), (14), (15), (16), (17).

O tempo de diagnóstico de DM entre os internos foi em média de 5,7 anos com a doença, entretanto não souberam precisar se do tipo 1 ou 2.

De modo geral, o tempo de pena a ser cumprida pela maioria dos entrevistados varia de 11 a 14 anos, período em que deverão permanecer reclusos, convivendo com a enfermidade.

O índice de massa corpórea (IMC) dos entrevistados indicou a presença de sobrepeso em mais da metade dos sujeitos de pesquisa. 
O acesso aos insumos como a medicação oral, seringas, insulina e glicosímetro, ao menos 19 responderam ter acesso fácil e 15 acrescentaram realizar exames de sangue com frequência, mesmo estando em ambiente de reclusão.

A entrevista semiestruturada permitiu conhecer, mais profundamente, o nível de entendimento sobre o diabetes dos internos, a convivência com a doença e as dificuldades enfrentadas no ambiente prisional.

Ao serem perguntados sobre o que é o diabetes, obteve-se da maioria resposta positivas demonstrando o conhecimento da enfermidade.

"O importante, na cadeia, é quando ela [DM] está alta e quando ela está baixa, porque a gente não sabe!" (RI 01)

"Aí, eu tenho glicose na cela... Já passei mal várias vezes, devido ela de cair! Tinha que ter a 45, a glicose! Ela é uma doença complicada!"(RI 02)

"[...] Não entendo nada, porque quando eu vim descobrir, já estava preso, já trabalhava... estava com sintoma dela já! É... Por enquanto, eu estou procurando me informar... sei que é uma doença muito perigosa, que eu tenho que tomar muito cuidado com ela. $O$ que eu consigo entender dela é só a parte da medicação. Tomo ela corretamente, conforme a orientação deles e nada mais! A gente sempre pediu uma palestra aí pra gente ficar mais interagido sobre a doença, mas nunca conseguimos nada!..."(RI 23)

Coates (18) igualmente demonstrou que o conhecimento é apenas uma das variáveis que pode influenciar no controle metabólico e que o estilo de vida e as crenças podem ter impacto no controle do diabetes.

Perguntados sobre se o fato de estar preso interfere sobre o controle da doença, as respostas variaram, desde a ausência da família como apoio, até a falta de atividade física.

"[...] Estou sendo bem cuidado aqui. Eu estou tendo um controle melhor... Eu deixo de estar praticando algo que não deva. $\mathrm{Na}$ alimentação, eu estou tendo acompanhamento adequado. Os cuidados que eu posso ter lá fora, eu continuo tendo aqui dentro. Aqui tem a dona Carol, o seu Henrique, a dona Bete, que me ajudaram muito; conseguiram esse aparelho pra mim! Eu estou com esse aparelho desde 25 de agosto! Nunca mais eu tive crises! Porque eu tinha crises horríveis! la parar no hospital! Eu passava internado... vinha muito alta e para baixar, aquela outra glicose não baixa! Essa que eu estou usando é muito bom! Aqui eu tenho um atendimento bom! Tem acompanhamento, 
tem alimentação... E a pessoa, quando ela descobre a diabetes, ela sabe o risco que ela está correndo... Ela sabe o que pode e o que não pode!..."(RI 04)

“[...] Falta de prática de exercício. Não se cuida por conta própria! Às vezes, tem que fazer isso por conta própria e não faz! Deixa a desejar pela sua própria saúde! Falta atividade! Trabalho! Só comendo e dormindo! Dá o nome de preso-porquinho! Come e dorme! É... Sedentarismo mesmo! Eu acho... Deixar preso aqui, obeso, dando assistência médica, dando remédio pra preso beber...!! Eu acho que o cidadão deveria vir pra cadeia pra pagar os seus erros, vir pra fazer algo, e não pra ficar parado em um quadrado com dezoito, vinte pessoas dentro! Também o banho de sol aqui da gente, é muito reduzido. Temos pouco tempo para fazer exercício no pátio."(RI 14)

"Não, senhora! Eu não recebo, porque não tem condições e não recebo visitas de parentes. Não recebo nada! Nada! Nada! Só recebo a alimentação da casa." (RI 20)

A família e os amigos têm papel fundamental e influenciam no controle da doença, especialmente quanto ao seguimento do tratamento, da dieta e na participação em um programa regular de exercícios. Pace, Nunes e Ucho-Vigo (19) demonstraram que as pessoas com Diabetes Mellitus, que tiveram apoio adequado de amigos e familiares, aderiram melhor às condutas de autocuidado.

Em pacientes institucionalizados, o cuidado familiar é reprimido e o controle e acompanhamento do DM ficam limitados à equipe de saúde local.

Além disso, o banho de sol limitado, associado à falta de realização de atividade física diária dificulta o convívio com a doença e agrava suas condições de saúde. No momento da soltura para o banho de sol, a realidade no complexo penitenciário não permite nada além de poucas horas de exposição solar dos presos, que realizam caminhadas ao redor do pátio, fazem corridas, jogam futebol, cantam, alguns participam de orações, e assim, aproveitam essa pequena parte do dia, sob supervisão de carcereiros.

Em casos de internação, a logística de transferência do preso para o ambiente hospitalar, muitas vezes implica no destacamento de equipes de segurança para vigiar o paciente enquanto perdurar a internação. Tal esquema onera, sobremaneira, o sistema da segurança pública quando não sobrecarrega o trabalho dos agentes, visto ser de 
321,50 a razão entre servidores da saúde e pessoas custodiadas na penitenciária da Papuda (9).

Na Penitenciária da Papuda, o uso da insulina glargina, tem gerado benefícios para alguns portadores com DM, em vista da diminuição de alterações glicêmicas e intercorrências clínicas provocadas pela doença (referência na entrevista do RI-04). Destaca-se, no entanto, que na ocasião da pesquisa, a insulina glargina não estava padronizada no SUS do Distrito Federal. A adoção da insulina diversa da padronizada ocorreu em função da resposta favorável que a terapêutica trouxe a esses pacientes, diminuindo consideravelmente as transferências dos internos enfermos para internação hospitalar, o que produz risco à segurança.

Também na vivência prisional a atividade física ao ar livre é reprimida, pois a segurança sobrepõe-se à necessidade de saúde.

Perguntados sobre o nível de satisfação com a alimentação na prisão em relação ao diabetes de que são portadores, a maioria respondeu negativamente.

"[...] A cadeia oferece uma comida que não é adequada para o diabete. A alimentação e a atividade física é importante! A gente fica quase o dia quase todo trancado na cela, assim, não tem como fazer exercício, né?!..."(RI 07)

"Recebo doze frutas, sendo maçã e banana, além de biscoito... Só! E, inclusive, eu queria que essas frutas passassem a ser quinze frutas, porque, daí, é uma por dia, né?! Como é só doze, não dá!!Recebo as coisas que eu posso comer mesmo! Recebo dinheiro pra comprar alguma coisa, um leite na cantina..."(RI 12)

"No controle, sim! Para o controle, sim! Mas pra meu desejo próprio, em necessidades de se alimentar, não! Eu pego as frutas direto! Eles mesmo me traz; me entregam direto!! Se não fosse essas frutas aí, eu estava pior! Apesar que é o seguinte: é... a comida, eu praticamente... o que eu mais como é só o feijão e um pouco de arroz! Quando a marmita vem, mais da metade eu jogo fora! Então, o que está realmente me sustentando é só o feijão e um pouco de arroz!"(RI 09)

"[...] Ah! Pra dizer a verdade, né?! Porque, às vezes, essa... alimentação vem gordurosa! Um dia vem muito sal! Um dia vem sem sal! Eu queria que botasse mais era verdura na alimentação. Eles botam mais é cenoura, cenoura, cenoura! E... Gordura e muito sal, né?!... O arroz... só vem o arroz e não tem nenhum tipo de salada; o arroz, ele gera açúcar, né?!... quando em quantidade. Eu já evito comer o máximo 
de arroz... O pão aqui só pão de doce! Quem é diabético não pode comer pão de doce... todynho, e é tudo doce! Então, pro diabético, ponto negativo! Eu acho também, que nós devemos receber também algum tipo de fruta! Eu não tenho uma dieta, não tenho uma alimentação que é adequada pro tipo de doença que eu tenho." (RI 01)

Foi apontado, nas entrevistas, descontentamento com a qualidade da alimentação no presídio. Uma grande quantidade de carboidrato associado à reduzida oferta ou ausência de verduras, aliado ao alto teor de gorduras na alimentação foram as principais queixas dos internos. Sabe-se que o consumo insuficiente de frutas, legumes e verduras estão entre os dez principais fatores de risco para a carga total global de doença em todo o mundo (20) Estudos experimentais e clínicos têm demonstrado que uma dieta com alto teor de gordura e baixo teor de fibras aumenta o risco de desenvolvimento da intolerância à glicose e do DM tipo 2 (21). Na realidade do Complexo Penitenciário da Papuda, a dieta é preparada para alimentar o coletivo de internos sem, contudo, haver o preparado diferenciado para aqueles que necessitam de uma refeição balanceada.

A alimentação recebida pelos presos contempla as principais refeições diárias: café da manhã, almoço e jantar. Os lanches nos intervalos são reprimidos e só os possui quem recebe visitas dos familiares. Recebe-se das visitas: biscoitos e frutas, limitadas pelo sistema carcerário a maçã, goiaba, pera e banana. Aos diabéticos há autorização para o recebimento de doze unidades de frutas desde que com prescrição médica, aos demais internos, apenas seis. Em um estudo realizado por Binswanger (22), ficou comprovado que doenças como a hipertensão arterial, o enfarte de miocárdio, e a diabetes têm uma prevalência mais elevada em indivíduos institucionalizados que no restante da população, enquanto o excesso de peso tem uma maior prevalência em reclusos condenados.

Ademais, é costume entre os internos, a utilização de determinadas frutas para a produção de bebidas, que ganham teor alcoólico a partir de sua fermentação, sendo necessária a adoção de restrições ao número e espécie de frutas. 


\section{Considerações finais}

O Complexo Penitenciário da Papuda não oferece condições adequadas para os internos masculinos portadores de enfermidades, porque as regras de segurança prevalecem sobre as orientações de saúde.

No caso do Diabetes Mellitus, a população institucionalizada no presídio estudado não recebe alimentação adequada, nem tempo suficiente e acompanhamento profissional para as atividades físicas necessárias ao controle da doença. O excesso de tempo em confinamento, por razões de segurança, em nada contribui para a melhoria das condições da doença ou o seu controle. No entanto, o atendimento médico e de enfermagem é garantido a esses pacientes e os medicamentos e demais insumos para o controle da glicose são oferecidos, não se constituindo, entretanto, razão para reconhecer que o sistema de saúde tem sua prática de cuidado com o DM instalado no ambiente do complexo penitenciário.

A exclusão, o afastamento familiar, a carência afetiva e o déficit alimentar, comuns no ambiente prisional, contribuem para o agravamento da doença e ferem 0 direito de cidadania dos presos. Eles não recebem dietas elaboradas por médicos ou nutricionistas ou a adequada dieta diabética, que inclui um lanche entre as refeições evitando assim eventuais hipoglicemias, utilizando-se o sistema prisional apenas de medicamentos para esse controle.

Os presos devem receber do sistema carcerário o atendimento necessário que Ihes promova e proteja a saúde e em caso de enfermidade, seja-Ihes restabelecida. Isso porque, como foi dito a princípio, o único direito que o preso perde é seu direito à liberdade, mantendo-se íntegros os demais direitos inerentes às pessoas e aos enfermos.

A população privada de liberdade é um grupo vulnerável, tanto pela ausência de liberdade e mobilidade quanto pelas condições sanitárias que envolvem presídios e instituições carcerárias. É preciso que a política de segurança nesses ambientes prisionais não exclua as prestações de serviços de saúde que essa comunidade necessita, como os demais segmentos da população brasileira, com integralidade e universalidade. 
Apesar das recomendações estarem amplamente documentadas quanto as consequências do excesso de peso estarem associadas a patologias que aumentam a morbidade e mortalidade na população, incluída a Diabetes Mellitus, os grupos populacionais em regime de reclusão permanecem ainda sem o devido acesso a uma alimentação saudável e equilibrada, assim como a prática regular de atividade física, que são fatores essenciais na prevenção da enfermidade.

A população carcerária tem seus direitos de cidadania reduzidos, quando não cerceados, apesar do arcabouço legal que lhes garante a integral garantia dos direitos sociais, especialmente o direito à saúde. Na atualidade, a prisão é uma tentativa de adaptação de um espaço físico a um sistema penal, que a todo o custo, busca na privação da liberdade a derradeira tentativa de uma verdadeira reinserção social. Assim, não faz sentido, afirmações encontradas na literatura (23) que defendem, em pleno Século XXI, que "em sede de remissão de pena, cabe atentar que é o condenado quem está em débito para com a sociedade e, portanto, deve arcar com todas as consequências de sua conduta delinquencial, inclusive com aquelas que lhe conferem a conta de eventuais falhas e lacunas da estrutura penitenciária".

É imperioso superar essas crenças e avançar na implantação da Política Nacional de Atenção Integral à Saúde das Pessoas Privadas de Liberdade no Sistema Prisional para que, cada vez mais, relatos como os narrados, sejam coisas do passado e seja pacífico que as restrições em nome da segurança do estabelecimento prisional não venha ferir o direito do preso à saúde, dificultando ao sistema da saúde adentrar ao sistema prisional para possibilitar a inserção da lógica do cuidado, mesmo em ambiente carcerário.

\section{Referências}

1 - Malagón-Oviedo RA, Czeresnia D. The concept of vulnerability and its biosocial nature. Interface (Botucatu). 2015; 19(53):237-49.

2 - Organização das Nações Unidas. Resolução 1984/47. Regras mínimas para o tratamento de prisioneiros. Disponível em http://www.dhnet.org.br/direitos/sip/onu/fpena/lex52.htm. Acesso em 30 jul 2016. 
3 - Brasil. Lei 7.210, de 11 de julho de 1984. Institui a Lei de Execução Penal. Disponível em http://www.planalto.gov.br/ccivil 03/leis/L7210.htm. Acesso em 30 jul 2016

4. Brasil. Constituição da República Federativa do Brasil de 1988. Brasília: Senado Federal, 2015.

5 - Brasil. Lei 8080, de 19 de setembro de 1990. Dispõe sobre as condições para a promoção, proteção e recuperação da saúde, a organização e o funcionamento dos serviços correspondentes e dá outras providências. Disponível em:

https://www.planalto.gov.br/ccivil 03/LEIS/L8080.htm. Acesso em 30 jul 2016

6 - Brasil. Portaria Interministerial no 1777, de 09 de setembro de 2003. Disponível em http://bvsms.saude.gov.br/bvs/saudelegis/gm/2003/pri 17770909 2003.html. Acesso em 30 jul 2016

7 - Brasil. Portaria Interministerial no 1.679 de 12 de agosto de 2013. Institui o Grupo de Trabalho Interministerial para elaboração da Política Nacional de Saúde no Sistema Prisional e o Comitê Técnico Intersetorial de Assessoramento e Acompanhamento da Política Nacional de Saúde no Sistema Prisional. Disponível em: http://bvsms.saude.gov.br/bvs/saudelegis/gm/2013/pri1679 1208 2013.html. Acesso em 30 jul 2016

8 - Brasil. Portaria Interministerial no 1 de 02 de janeiro de 2014. Institui a Política Nacional de Atenção Integral à Saúde das Pessoas Privadas de Liberdade no Sistema Prisional (PNAISP) no âmbito do Sistema Único de Saúde (SUS). Disponível em http://bvsms.saude.gov.br/bvs/saudelegis/gm/2014/pri0001 0201 2014.html. Acesso em 30 jul 2016

9 - Brasil. Ministério da Justiça. Levantamento Nacional de Informações Penitenciárias INFOPEN, dez, 2014. Disponível em http://www.justica.gov.br/seus-direitos/politicapenal/infopen dez14.pdf. Acesso em 30 jul 2016

10.- Gil, A. C. O questionário. In: - Métodos e técnicas de pesquisa social. São Paulo: Atlas, 1995. p. 124-132

11 - Minayo, MCS. et al. (orgs.). Pesquisa social: teoria, método e criatividade. 22. ed. Petrópolis: Vozes, 2003. p. 9-29.

12. Canzonieri, AM. Metodologia da Pesquisa Qualitativa em Saúde. Petrópolis: Vozes, 2011

14 - Carvalho ML, Biondi EJ, Veiga LP Estudo transversal sobre prevalencia da infeccao pelo HIV no sistema penitenciario do Rio de Janeiro - 1997. In: III Congresso Brasileiro de Epidemiologia. Rio de Janeiro; 1998 Oct 15-19; Armazem das Letras Grafica e Editora; 1998 
15 - Strazza LME, Carvalho HB. Estudo de comportamento associado a infeccao pelo HIV e HCV em detentas de um presidio de Sao Paulo, Brasil. Cadernos de Saude Publica; 23 (1):197-205, 2007.

16 - Young M, Waters B, Falconer T, O'Rourke P. Opportunities for health promotion in the Queensland women's prison system. Australian New Zealand Journal of Public Health, 29 (4):324-327, 2005

17 - Doreen K, Kinner SA, Butler T. Young prisioners: An important group for health research? Journal of Correctional Health Care 2010; 16 (4):322-327.

18 - Coates, V. E. Educational issues relating to people with long term health problems. In:___. Education for patient sand clients. London: Rutledge, 1999: 135-160.

19 - Pace, A. E.; Nunes, P. D.; Ochoa-Vigo, K. O conhecimento dos familiares acerca da problemática do portador de diabetes mellitus. Revista Latino-Americana de Enfermagem, 11 (3): 312-319, maio/jun. 2003. Disponível em:

<https://www.nescon.medicina.ufmg.br/biblioteca/imagem/0179.pdf>. Acesso em: 9 set. 2014.

20 - World Health Organization. The world health report 2002: reducing risks, promoting healthy life. Geneva, 2002. Disponível em:

<http://whqlibdoc.who.int/publications/2002/9241562072.pdf>. Acesso em: 8 set. 2014

21 - Molena-Fernandes, C. A. M. et al. A importância da associação de dieta e de atividade física na prevenção e controle do Diabetes mellitus tipo 2. Acta Scientiarum: Health Sciences, 27(2):195-205, 2005. Disponível em:

<http://dx.doi.org/10.4025/actascihealthsci.v27i2.1427>. Acesso em: 8 set. 2014.

22 - Binswanger I, Krueger P, Steiner J. Prevalence of chronic medical conditions among jail and prison inmates in the USA compared with the general population. Journal of Epidemiology Community Health, 2009; 63:912-919.

23 - Kuehne, Maurício. Teoria e prática da aplicação da pena. Curitiba: Juruá, 1998, p.

Recebida em: 23.9.2017

Reapresentado em: 2.11.2017

Aprovada em: 26.12.2017

Como citar este artigo:

Ferreira MCO. Os sentidos de viver com diabetes mellitus na carceragem: relatos de prisioneiros no Complexo Penitenciário da Papuda, Brasília-DF. Revista Cadernos Ibero-Americanos de Direito Sanitário. 2017 out./dez, 6(4):41-54. 